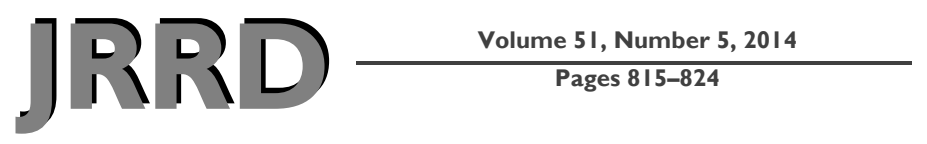

\title{
Effect of low-intensity direct current on expression of vascular endothelial growth factor and nitric oxide in diabetic foot ulcers
}

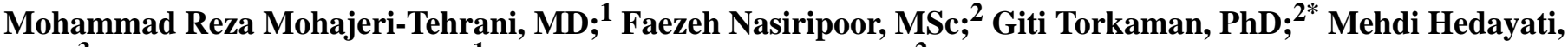 \\ PhD; ${ }^{3}$ Zohreh Annabestani, MD; ${ }^{1}$ Mohammad Reza Asadi, MSc $^{2}$ \\ ${ }^{1}$ Endocrinology and Metabolism Research Center, Tehran University of Medical Sciences, Tehran, Iran; ${ }^{2}$ Physical Therapy \\ Department, Faculty of Medical Sciences, Tarbiat Modares University, Tehran, Iran; ${ }^{3}$ Cellular and Molecular Research \\ Center, Research Institute for Endocrine Sciences, Shahid Beheshti University of Medical Sciences, Tehran, Iran
}

\begin{abstract}
This study investigated the effect of low-intensity cathodal direct current on the release of plasma vascular endothelial growth factor (VEGF) and nitric oxide (NO) in diabetic foot ulceration. Twenty type 2 diabetic patients with foot ulceration and thirteen age-matched healthy subjects were enrolled. Patients were randomly assigned to electrical stimulation (ES) $(n=10)$ or sham ES (placebo, $n=10)$ groups. The ES group received cathodal direct current $(1.48+/-0.98 \mathrm{~mA})$ for $1 \mathrm{~h} / \mathrm{d}$, $3 \mathrm{~d} /$ wk for $4 \mathrm{wk}$ (12 sessions). Blood samples were collected for VEGF and NO measurement in the first and last treatment sessions before and after intervention. Wound surface area and skin temperature were measured at the 1st, 6th, and 12th sessions. VEGF significantly increased in the ES group compared with the placebo group after the 1 st $(106.61+/-79.50$ and $40.88+/-26.20$, respectively) and 12th sessions (109.28 +/67.30 and $34.79+/-13.20$, respectively). NO level also increased significantly in the ES group compared with the placebo group after the 12th session $(44.21+/-14.00$ and $35.25+/-$ 11.00 , respectively). The increase of skin temperature was significantly higher in the ES group than the placebo group. Application of low-intensity ES increases the expression of VEGF and NO, which may lead to improved blood flow and tissue temperature and, consequently, wound healing in diabetic foot ulceration.
\end{abstract}

Key words: diabetes, diabetic foot ulceration, direct current, electrical stimulation, foot ulcer, NO, skin temperature, vascular endothelial growth factor, VEGF, wound healing.

\section{INTRODUCTION}

Diabetic foot ulceration (DFU) is one of the most significant complications of diabetes [1]; it is caused by vascular disorders, neuropathy, and infection [2]. These ulcers have a significant effect on the health status of diabetic patients. The rate of lower-limb amputation is 15 times higher in diabetic patients than nondiabetics, and more than 50 percent of diabetic patients with an amputation need subsequent amputation of the contralateral limb within $5 \mathrm{yr}$ of the loss of the first leg [3]. Diabetic wounds are chronic open sores that are hard to heal because of poor blood circulation at the wound sites [4-5].

One of the most important reasons for delayed healing in DFU is lack of adequate blood supply due to

Abbreviations: $\% \downarrow$ WSA $=$ percentage decrease in wound surface area, $\mathrm{ANOVA}=$ analysis of variance, $\mathrm{DFU}=$ diabetic foot ulceration, ELISA = enzyme-linked immunosorbent assay, ES = electrical stimulation, $\mathrm{NO}=$ nitric oxide, $\mathrm{SD}=$ standard deviation, TENS $=$ transcutaneous electrical nerve stimulation, VEGF $=$ vascular endothelial growth factor, $\mathrm{WSA}=$ wound surface area.

*Address all correspondence to Giti Torkaman, PhD; Physical Therapy Department, Tarbiat Modares University, Tehran, I. R. Iran; +98-21-82884509; fax: +98-21-88006544. Email: torkamg@modares.ac.ir http://dx.doi.org/10.1682/JRRD.2013.08.0174 
impaired angiogenesis [5-6]. Angiogenesis, an important part of the wound healing process, occurs during the proliferative phase of wound healing. It improves the blood flow in the wound site by new vessel formation and vascular hyperpermeability [7]. Several growth factors, including basic fibroblastic growth factor, plateletderived growth factor and nerve growth factor, and vascular endothelial growth factor (VEGF), have been implicated as effective mediators of angiogenesis. VEGF, as a direct angiogenic factor, has a main role in angiogenesis [8-11]. Evidence exists that expression of growth factors such as VEGF reduce the occurrence of DFU [12-13].

Experimental studies demonstrate that electrical stimulation (ES) upregulates VEGF expression at the wound site [14-15]. In a clinical study, Bevilacqua et al. examined the effect of frequency modulated ES and transcutaneous electrical nerve stimulation (TENS) on the release of VEGF in diabetic and nondiabetic subjects [16]. They reported that acute plasma VEGF enhancement occurred during frequency-modulated ES in both the diabetic and nondiabetic subjects.

Nitric oxide (NO) is another mediator that plays an important role in the wound healing process [17]. NO synthesis occurs during wound healing and regulates important parts of wound healing, such as chemotaxis, angiogenesis, cellular proliferation, and epithelialization [18-19]. Moreover, NO, as a vasodilator, has an important role in the increase of blood flow to ischemic tissue [20-23]. Available evidence demonstrate that NO level reduces in the wound environment in diabetic animals [24-25]. However, no clinical study was found in the literature that investigated the effect of ES on VEGF and NO expression in DFU.

ES has been shown to promote chronic wound closure and healing rate [26-27]. Although the mechanism of this useful effect of ES on wound healing is not completely clear, it has been shown that fibroblasts, keratinocytes, macrophages, and endothelial cells release VEGF into the wound environment [8], and these cells migrate toward negative polarity (cathode) in an electrical field $[26,28]$. Asadi et al. reported that applying sensory ES through the cathode to the wound site has a greater effect on the expression of VEGF in incisional wounds [14].

Therefore, we conducted this study to investigate the effect of applying cathodal direct current ES at sensory threshold intensity on the release of plasma VEGF and NO in type 2 diabetic patients with foot ulceration. We hypothe- sized that the application of this current would promote skin temperature and the healing process in DFU.

\section{METHODS}

\section{Study Design and Patients}

Twenty type 2 diabetic patients with foot ulceration and thirteen age-matched healthy subjects were recruited to participate in this study. All subjects were living at home and were allowed normal activities of daily living during the 4 wk study period. The inclusion criteria for patients with DFU were as follows: Wagner classification DFU 2, age 40-60 yr, mild to moderate diabetic neuropathy, ankle-brachial index $>0.7$, and wound surface area (WSA) $>1.5 \mathrm{~cm}^{2}$. Subjects were excluded from the study if they had a fracture in a lower limb, severe infection, malignancy, kidney failure, skin diseases, osteomyelitis, pregnancy, any drug administration or therapeutic device that could enhance wound healing (within the last $30 \mathrm{~d}$ ), or medical condition for which ES is contraindicated.

\section{Electrical Stimulation Protocol}

Patients were randomly assigned to a group that received either ES (ES group, $n=10$ ) or sham ES (placebo group, $n=10$ ) with a random number prepared by an independent person. Patients and the person collecting and determining the blood samples were blinded to grouping. In the ES group, direct current ES was applied at sensory threshold intensity $(1.48 \pm 0.98 \mathrm{~mA})$ for $1 \mathrm{~h} / \mathrm{d}$, $3 \mathrm{~d} / \mathrm{wk}$ for $4 \mathrm{wk}$ (12 sessions). To decrease the risk of electrochemical burns that can be caused by sensory nerve impairment in diabetic patients and, consequently, can increase the reported intensity for sensory threshold by patients, we used a sensory threshold ratio from the forearm to the leg and the thigh to the leg. Before the main study, a pilot study was performed to determine these ratios in five age-matched healthy subjects. These ratios were used to adjust the correct sensory threshold intensity in the ES group. An active carbon rubberized electrode $(3 \times 4 \mathrm{~cm})$ was placed just outside the ulcer surface area. A dispersive electrode $(4 \times 6 \mathrm{~cm})$ was placed approximately $20 \mathrm{~cm}$ proximal to the active electrode and far from the wound on the proximal region of the leg. The polarity of the active electrode was negative (cathode) during the treatment period. This setting was selected according to previous experimental studies [14]. In the placebo group, the treatment procedure was the 
same as that described for the ES group, but the current intensity was zero. All patients (ES and placebo) received similar conventional therapy that included debridement, cleaning of the wound with saline, dressing, and systemic antibiotic therapy. The BTL-5000 series (BTL Industries, Ltd; Staffordshire, United Kingdom) was used as the ES device in this study.

To compare the basal level of VEGF and NO in diabetic patient participants with normal values, blood samples were taken from 13 nondiabetic age-matched healthy subjects.

\section{Blood Sample Preparation and Determination of Vascular Endothelial Growth Factor and Nitric Oxide Levels}

In the ES and placebo groups, on the first and last (12th) treatment session, before and after intervention, and in the healthy subjects (only once), blood samples were taken for NO and VEGF measurement.

Blood samples were centrifuged at 1,200 rpm for $15 \mathrm{~min}$ at $4^{\circ} \mathrm{C}$. Plasma was collected and stored at $-80^{\circ} \mathrm{C}$ until use. VEGF concentration was measured using an enzyme-linked immunosorbent assay (ELISA) kit (Human VEGF ELISA, Cusabio Biotech Inc; Wuhan, China) with a sensitivity of $0.8 \mathrm{pg} / \mathrm{mL}$. NO concentration was determined using an $\mathrm{NO}$ assay kit (Colorimetric Assay, Abnova; Walnut, California) with a sensitivity of $2.5 \mu \mathrm{M}$.

\section{Measurement of Skin Temperature}

Skin temperature was measured on the dorsal and plantar surfaces of the foot, distal to the wound and at three points on each surface. Moreover, skin temperature was measured on the distal, middle, and proximal parts of the leg. A digital multimeter (Digital HiTester, model 3801, Hioki EE Corp; Nagano, Japan) was used to measure the skin temperature before and after the application of ES at the 1st, 6th, and 12th sessions. The mean temperature of all six points on the dorsal and plantar surfaces and the mean temperature of the three parts of the leg were used in the statistical analysis.

\section{Measurement of Wound Surface Area}

WSA (length $\times$ width) was measured at the 1 st, 6 th, and 12th treatment days by the use of a metric ruler and a digital camera. The percentage decrease in WSA (\% $\downarrow$ WSA) for the 6 th and 12th treatment sessions was calculated for each patient by $\% \downarrow$ WSA $=[$ (initial WSAWSA on each day)/initial WSA] $\times 100$.

\section{Statistical Analysis}

The Kolmogorov-Smirnov test demonstrated that the VEGF, NO values, skin temperature, and WSA were normally distributed in the groups $(p>0.05)$. Therefore, repeated-measures analyses of variance (ANOVAs), paired $t$-tests (to compare data in each group), and independent $t$-tests (to compare data in two groups) were used for data analysis. To compare the basal level of VEGF and NO in diabetic patient participants with the normal values in healthy subjects, ANOVA and the Tukey test were used. Statistical analysis was performed using SPSS software, version 16.0 (IBM Corporation; Armonk, New York). We considered statistical significance as $p \leq 0.05$.

\section{RESULTS}

Detailed demographic characteristics of the patients are presented in Table 1. The subjects' baseline characteristics did not significantly differ between the two groups $(p>0.05)$.

\section{Plasma Vascular Endothelial Growth Factor Protein Level}

The basal level of VEGF in the two diabetic groups (ES and placebo) was higher than that in the healthy subject group, and this increase was significant between the ES and healthy group (Figure 1). The plasma level of VEGF protein in both diabetic groups on the 1st and the 12th treatment days is shown in Table 2. At the 1st day before intervention, there was no significant difference between the ES and placebo groups $(p=0.3)$, but after intervention, VEGF concentration was significantly increased in the ES group compared with the placebo group $(p=0.03)$. At the 12th day before intervention, there was no significant difference between ES and placebo groups $(p=0.3)$, but after intervention, VEGF concentration in the ES group was significantly higher than in the placebo group $(p=0.005)$. The difference percentage of VEGF was significantly increased after ES application for 12 sessions compared with the placebo group $(p=0.04)$. There was no significant difference for plasma VEGF level before and after $4 \mathrm{wk}$ in each group. In contrast to the ES group, the plasma VEGF level of the placebo group showed a significant decrease in the 1st and 
Table 1.

Baseline characteristics of diabetic patient in two diabetic groups (electrical stimulation [ES] and placebo) and healthy group. (Data shown as mean \pm standard deviation unless otherwise indicated.)

\begin{tabular}{lccc}
\hline Characteristic & \multicolumn{1}{c}{ Group } & \\
\cline { 2 - 4 } & ES $(\boldsymbol{n}=\mathbf{1 0})$ & Placebo $(\boldsymbol{n}=\mathbf{1 0})$ & Healthy $(\boldsymbol{n}=\mathbf{1 3})$ \\
\hline Age (yr) & $57 \pm 3.2$ & $56.1 \pm 2.9$ & $54.4 \pm 1.7$ \\
Sex (\%) & 80 & 90 & 100 \\
$\quad$ Male & 20 & 10 & 0 \\
$\quad$ Female & $14.7 \pm 1.5$ & $12 \pm 1$ & - \\
Wound Duration (mo) & $2.48 \pm 0.97$ & $2.43 \pm 0.39$ & - \\
Wound Surface Area (cm $\left.{ }^{2}\right)$ & & & - \\
Wound Location (\%) & 80 & 70 & $1.1 \pm 0.1$ \\
$\quad$ Left & 20 & 30 & $1.2 \pm 0.1$ \\
$\quad$ Right & & & - \\
Ankle-Brachial Index & $0.8 \pm 0.2$ & $0.9 \pm 0.1$ & $0.9 \pm 0.1$ \\
$\quad$ Left & $0.9 \pm 0.2$ & & \\
Right &
\end{tabular}

12th sessions and also before and after the 12 sessions ( $p=$ $0.01,0.001$, and 0.005 , respectively).

\section{Plasma Nitric Oxide Level}

The basal level of NO in the two diabetic groups (ES and placebo) was significantly lower than that in the healthy subject group (Figure 2). The plasma level of NO in both the diabetic groups at the 1st and 12th treatment session is shown in Table 3. Comparison of the basic mean of NO between the two groups before the 1st treatment session showed no significant difference $(p=$

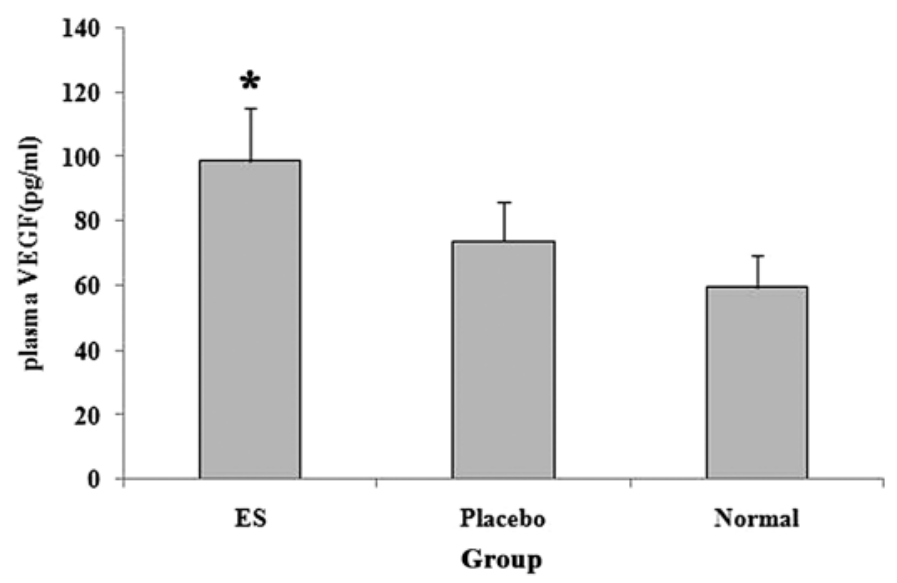

Figure 1.

Basal level of vascular endothelial growth factor (VEGF) in two diabetic groups (electrical stimulation [ES] and placebo) and healthy group (normal). *Significant difference between ES and placebo.
0.80). The mean value of NO in the ES group did not significantly increase between the 1st and 12th sessions; in contrast, NO significantly decreased in the placebo group (before the 1st and after the 12th session, $p=0.002$ ). The NO level in the ES group was significantly higher than that in the placebo group after the 12th session $(p=0.04)$.

\section{Changes in Skin Temperature}

Changes in foot skin temperature for the ES and placebo groups are shown in Figure 3. After application of ES, a significant increase was seen in the foot skin temperature at the 1st, 6 th, and 12 th sessions $(5.4 \% \pm 0.6 \%$, $8.7 \% \pm 1.2 \%$, and $11.5 \% \pm 1.6 \%$, respectively). These increases in ES group were significant between different sessions and also between the same sessions compared with placebo group ( $p<0.001$ for all tests). The foot skin temperature showed no significant difference for placebo group. Changes in leg skin temperature for ES and placebo groups are shown in Figure 4. After application of $\mathrm{ES}$, a significant increase was seen in the leg skin temperature at the $1 \mathrm{st}, 6 \mathrm{th}$, and 12 th sessions $(9.37 \% \pm$ $2.40 \%, 6.69 \% \pm 4.48 \%$, and $6.22 \% \pm 3.45 \%$, respectively). These increases were significant between same sessions compared with placebo group ( $p<0.001, p=$ 0.002 , and $p<0.001$, respectively).

\section{Changes in Wound Surface Area}

$\% \downarrow$ WSA for the ES and placebo groups is presented in Figure 5. In the ES group, \% $\downarrow W S A$ on the 12th day was significant compared with the 6th day $(p=0.05)$. In the placebo group, no significant difference was observed 
Table 2.

Plasma level of vascular endothelial growth factor $(\mathrm{pg} / \mathrm{mL})$ in both diabetic groups at 1 st and 12th treatment session. (Data shown as mean \pm standard deviation.)

\begin{tabular}{lcccrrr}
\hline \multirow{2}{*}{ Group } & \multicolumn{2}{c}{ Day 1 } & & \multicolumn{2}{c}{ Day 12 } \\
\cline { 2 - 3 } \cline { 5 - 6 } & Before & After & & Before & $109.28 \pm 67.30^{\dagger}$ \\
\hline ES & $92.28 \pm 53.20$ & $106.61 \pm 79.50^{*}$ & & $98.54 \pm 63.30$ & $34.79 \pm 13.20$ \\
Placebo & $70.58 \pm 33.10$ & $40.88 \pm 26.20$ & & $73.77 \pm 29.70$ & 34.79 \\
\hline
\end{tabular}

*Significant difference compared with placebo group on 1st session.

†Significant difference compared with placebo group on 12th session.

$\mathrm{ES}=$ electrical stimulation.

in $\% \downarrow$ WSA between the 6 th and 12 th days. $\% \downarrow$ WSA on the 6th and 12th days in the ES group was greater than in the placebo group, and this increase was near the significant level on the 12th day $(p=0.07)$.

\section{DISCUSSION}

Despite the strong evidence supporting the useful effects of ES for managing chronic wounds [29-32], the mechanisms of these effects are not yet fully understood. VEGF, as an important angiogenic factor, and NO, as a vasodilator, play a potent role in the formation of new vessels (angiogenesis) in the wound healing process [811,17]. There is evidence that the expression of VEGF and NO is reduced in patients with diabetes, and this diminution is associated with delayed healing in the wounds [12,24-25]. The results of the present study

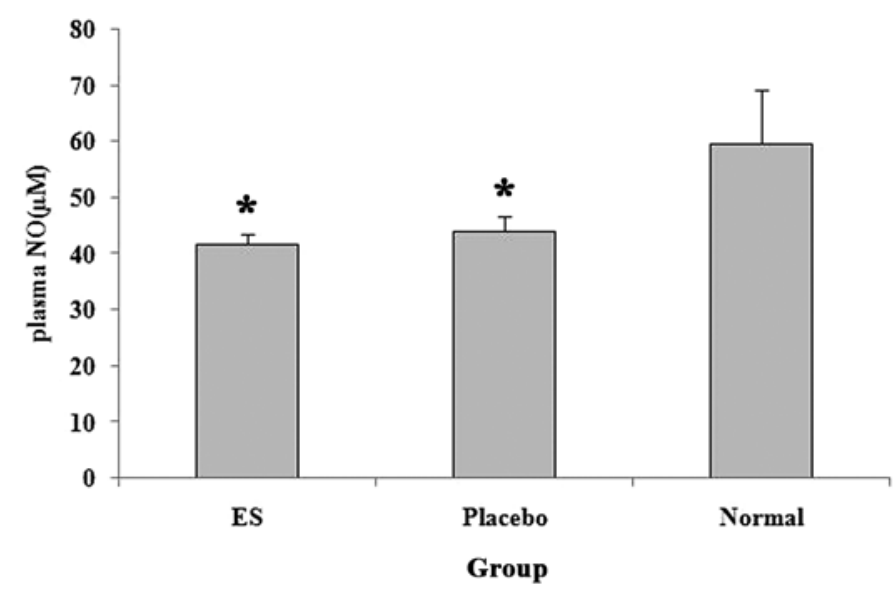

Figure 2.

Basal level of nitric oxide (NO) in two diabetic groups (electrical stimulation [ES] and placebo) and healthy group (normal). "Significant decrease compared with healthy. showed that the plasma level of VEGF in patients with DFU was higher than that in normal age-matched subjects, but the NO level in these patients was lower than that in the normal subjects. The obtained results showed that after $1 \mathrm{~h}$ of ES application (1st and 12th sessions), the plasma level of VEGF was increased significantly compared with the placebo group.

Several investigations have reported that ES can enhance angiogenesis by the upregulation of angiogenic factors, such as VEGF and FGF-2 [14,16,33]. Morris et al. reported that ES (square wave pulsed direct current, $11 \mathrm{~mA}$ amplitude, $40 \mathrm{~ms}$ interpulse interval, 5 or $110 \mu \mathrm{s}$ pulse duration) induced a significant increase in VEGF level in ischemic wounds in the ears of rabbits [15]. Asadi et al. reported that applying cathodal direct current at sensory intensity induces significant enhancement of VEGF [14] and FGF-2 [33] levels in incisional wounds. In a clinical study, Bevilacqua et al. investigated the effect of frequency-modulated ES and TENS on the release of VEGF in diabetic and nondiabetic subjects. They observed a significant increase in plasma VEGF concentration during frequency-modulated ES in both the nondiabetic and diabetic subjects. These investigators suggested that frequency-modulated ES may have stimulated the endothelium of the vasa nervorum to release VEGF into circulation [16]. Another clinical study by Sebastian et al. examined the effects of ES on wound healing in cutaneous wounds caused by punch biopsy in 20 healthy volunteers. They reported that cutaneous wounds receiving ES had higher VEGF expression, and this demonstrated that angiogenesis further upregulated following ES [34].

The mechanism by which ES stimulates the release of VEGF is still not well known. It has been suggested that the ES by galvanotaxis effect (directional migration of cells) induces the increase of attraction of releasing cells of VEGF (endothelial cells, fibroblasts, macrophages, 
JRRD, Volume 51, Number 5, 2014

Table 3.

Plasma level of nitric oxide $(\mu \mathrm{M})$ in both diabetic groups at 1st and 12th treatment session. (Data shown as mean \pm standard deviation.)

\begin{tabular}{lccccc}
\hline \multirow{2}{*}{ Group } & \multicolumn{2}{c}{ Day 1 } & & \multicolumn{2}{c}{ Day 12 } \\
\cline { 2 - 3 } \cline { 5 - 6 } & \multicolumn{1}{c}{ Before } & After & & Before & After \\
\hline ES & $41.70 \pm 5.40$ & $40.99 \pm 10.60$ & & $41.50 \pm 14.20$ & $44.21 \pm 14.00^{*}$ \\
Placebo & $44.02 \pm 8.50$ & $44.30 \pm 7.90$ & & $39.17 \pm 8.20$ & $35.25 \pm 11.00^{\dagger}$ \\
\hline
\end{tabular}

${ }^{*}$ Significant difference compared with placebo group on 12 th session.

${ }^{\dagger}$ Significant difference compared with baseline on 1st session in placebo group.

$\mathrm{ES}=$ electrical stimulation.

and keratinocytes) toward the wound site [14,35-36]. In addition, ES may stimulate the endothelium of the vasa nervorum to release VEGF into circulation [16]. Our finding in the present study has shown that applying cathodal direct current at sensory threshold may upregulate the expression of VEGF in patients with DFU, especially instantaneous after application of ES. Because of the high standard deviation (SD) of plasma VEGF, it may be better to measure this protein directly via tissue sampling from the wound. However, tissue sampling is an invasive method and it will interfere with the healing process. The cause of the decrease in VEGF on the 1st and 12th days in the placebo group is not clear and should be clarified in future studies.

We found that ES also increases the plasma level of NO in patients with DFU; however, this increase was sig-

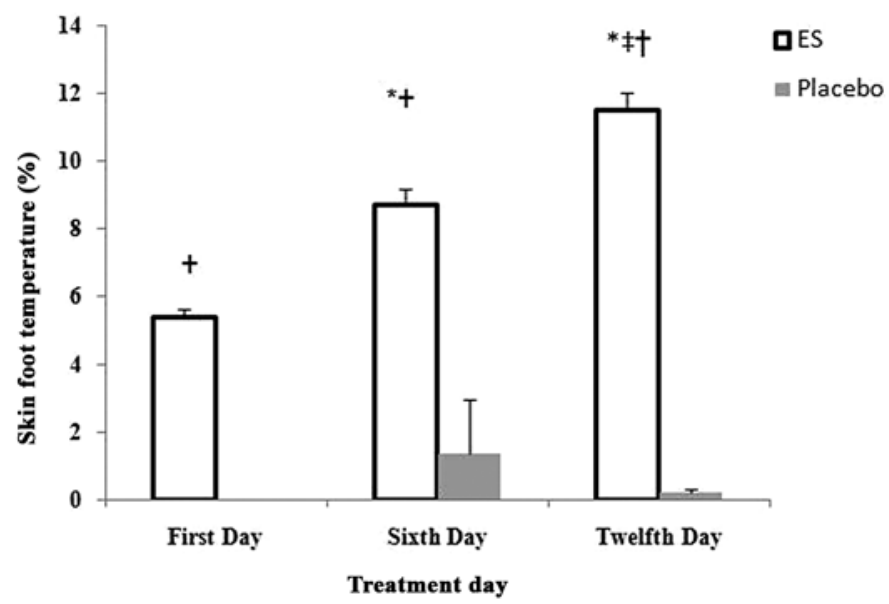

Figure 3.

Percentage change in foot skin temperature on 1st, 6th, and 12th days for two experimental groups (electrical stimulation [ES] and placebo). * Significant increase compared with 1st day of ES group. ${ }^{\dagger}$ Significant increase compared with placebo group. ${ }^{\ddagger}$ Significant increase compared with 6th day of ES group. nificant only after the 12th session of ES application compared with placebo group. Little evidence exists for the effect of ES on NO expression in diabetic patients. Petrofsky et al. proposed that ES increases blood flow in the wound site through an increase in the release of the vasodilator NO [37]. In addition, Ferrer et al. in an experimental study reported that ES induces vasodilation by release of NO [38]. The mechanism by which ES increases the NO plasma level is still not well understood. With respect to NO released by the endothelium of vessels into circulation [39], ES may be stimulating the endothelial cells to release NO in blood circulation. In addition, it is possible that ES induces ion flows that can trigger a change of membrane potential and enhance the release of NO [37]. One of the most important complications of patients with chronic wounds such as DFU is delayed wound closure. The use of low-intensity ES can be effective in promoting wound closure by mimicking the internal bioelectric system within the wound site.

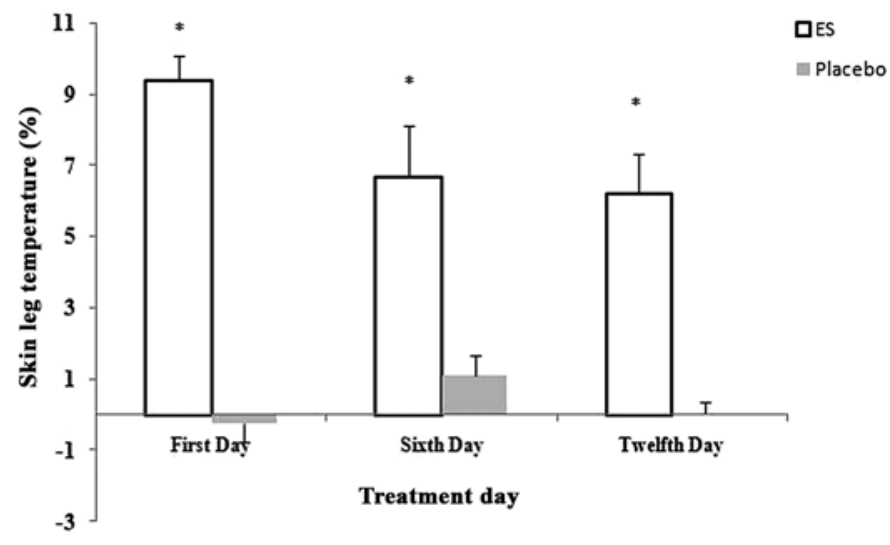

Figure 4.

Percentage change in leg skin temperature on 1st, 6th, and12th days in two experimental groups (electrical stimulation [ES] and placebo). 'Significant increase compared with placebo group. 


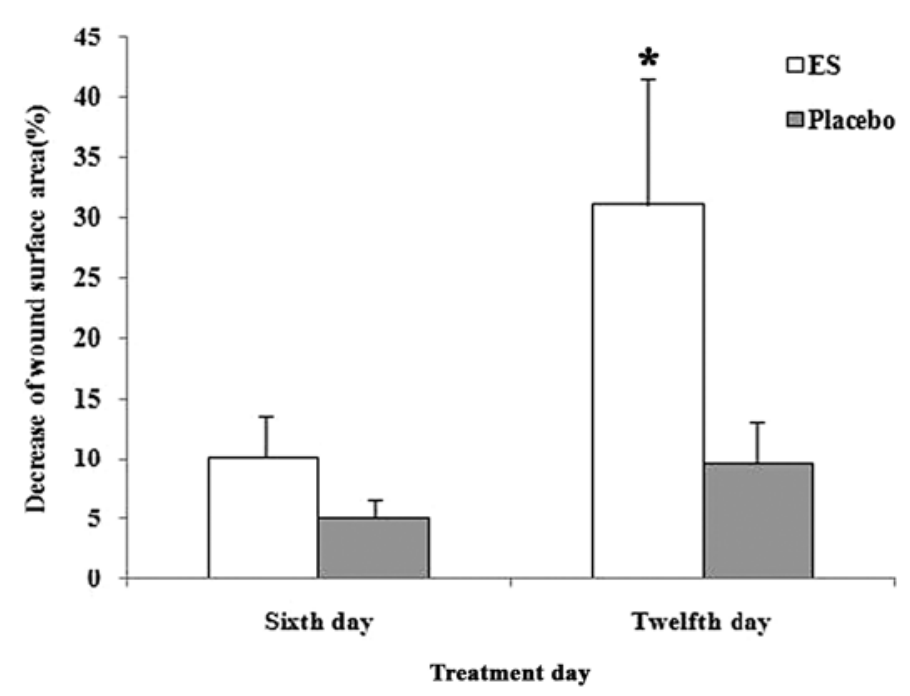

Figure 5.

Percentage decrease of wound surface area on 6th and 12th days in two experimental groups (electrical stimulation [ES] and placebo). *Significant difference compared with 6th session in ES group.

There are some reports that ES promotes blood perfusion and wound closure in diabetic patients [30-32]. The results of the present study coincide with previous studies. Our results indicated that 12 sessions of ES applied to diabetic ulcers reduced the WSA by more than 31 percent, which was three times greater than that observed in the placebo group (mean \pm SD decrease $=9.6 \% \pm 8.3 \%$ ). After ES application, this reduction in wound area is very important because $14.17 \pm 1.50 \mathrm{mo}$ had passed since the creation of the wounds and repair was delayed. In this study, we found that the difference between the ES and placebo groups for $\% \downarrow$ WSA on the 12 th session was near statistical significance $(p=0.07)$. Whereas our study was conducted with a relatively small sample, the inclusion of additional subjects with DFU would certainly have improved the statistical power of our results and a statistically significant difference might have been observed between the ES and placebo groups for $\% \downarrow$ WSA on the 12 th session. In this study, WSA was measured because it is a completely noninvasive, inexpensive, and accurate method without any intervention in the wound space, whereas measuring the volume of the wound is important especially in larger wounds. The improvement of ulcer healing and skin temperature seen in this study may be owing to the increase of blood flow within wound site. It appears that ES can increase wound circulation by enhancement of VEGF and NO plasma concentration in these patients. Petrofsky et al. found a large increase in skin blood flow induced by the release of NO during ES in humans [37]. Increase in skin temperature in the dorsal and plantar surfaces of the feet and legs of diabetic patients can indicate increased skin blood flow following the application of ES. On the other hand, this increase can lead to a greater increase in skin blood flow. Lawson and Petrofsky confirmed that following treatment with global heat and ES to the wound, skin blood flow

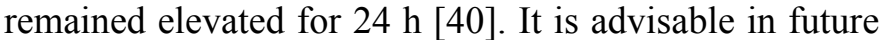
studies to assess the effect of heating the skin and simultaneously applying ES to increase VEGF and NO. In this study, for some limitations, we were unable to measure the skin blood flow directly. We recommend that future studies measure blood flow and transcutaneous oxygen pressure to clarify the effect of ES on the skin circulation of DFUs. This study, however, only examined a small number of subjects; additional studies must be conducted with adequate sample size and different DFU grades to determine the effect of ES on angiogenic factors, skin blood flow, and promotion of healing and their correlations in DFUs.

\section{CONCLUSIONS}

In summary, the results of the present study support the use of ES in the treatment of DFUs. This study showed that ES (with parameters used in this study) may effectively increase the plasma level of VEGF and NO in patients with DFU. Therefore, it seems the application of cathodal direct current ES (at sensory threshold intensity) can induce improvement in skin temperature and wound healing in DFU, probably by stimulating the release of VEGF and NO and increasing blood flow following the expression of these angiogenic factors.

\section{ACKNOWLEDGMENTS}

\section{Author Contributions:}

Study concept and design: G. Torkaman, F. Nasiripoor. Acquisition of data: F. Nasiripoor, Z. Annabestani. Analysis and interpretation of data: F. Nasiripoor, G. Torkaman, M. R. Mohajeri-Tehrani.

Drafting of manuscript: F. Nasiripoor, G. Torkaman, M. R. Asadi, M. Hedayati.

Critical revision of manuscript for important intellectual content:

G. Torkaman, M. R. Mohajeri-Tehrani. 
Statistical analysis: F. Nasiripoor, G. Torkaman.

Obtained funding: G. Torkaman.

Administrative, technical, or material support: G. Torkaman,

M. R. Mohajeri-Tehrani, M. Hedayati.

Study supervision: G. Torkaman, M. R. Mohajeri-Tehrani.

Financial Disclosures: The authors have declared that no competing interests exist.

Funding/Support: This material was based on work supported by a grant from the Postgraduate Studies and Research Program, Physical Therapy Department at Tarbiat Modares University, Tehran, Iran. Institutional Review: This randomized controlled trial was approved by the Medical Ethics Commission of Tarbiat Modares University. All study protocols were explained to each subject, and participants signed an informed consent statement if they agreed to participate in the study.

Participant Follow-Up: The authors do not plan to inform the participants of the publication of this study because contact information is unavailable.

\section{REFERENCES}

1. Schaper NC, Prompers LM, Huijberts MS. Treatment of diabetic foot ulcers. Immunol Endocr Metab Agents Med Chem. 2007;7:95-104. http://dx.doi.org/10.2174/187152207779802482

2. Akbari CM, Macsata R, Smith BM, Sidawy AN. Overview of the diabetic foot. Semin Vasc Surg. 2003;16(1):3-11. [PMID:12644970] http://dx.doi.org/10.1016/S0895-7967(03)70002-7

3. Reiber GE, Boyko EJ, Smith DG. Lower extremity foot ulcers and amputations in diabetes. In: Harris MI, Cowie C, Stern MP, editors. Diabetes in America. 2nd ed. NIH Publication No. 95-1468. Bethesda (MD): National Diabetes Data Group of the National Institute of Diabetes and Digestive and Kidney Diseases, National Institutes of Health; 1995. p. 409-28.

4. Zimny S, Dessel F, Ehren M, Pfohl M, Schatz H. Early detection of microcirculatory impairment in diabetic patients with foot at risk. Diabetes Care. 2001;24(10): 1810-14. [PMID:11574447] http://dx.doi.org/10.2337/diacare.24.10.1810

5. Martin A, Komada MR, Sane DC. Abnormal angiogenesis in diabetes mellitus. Med Res Rev. 2003;23(2):117-45. [PMID:12500286] http://dx.doi.org/10.1002/med.10024

6. Brem H, Jacobs T, Vileikyte L, Weinberger S, Gibber M, Gill K, Tarnovskaya A, Entero H, Boulton AJ. Woundhealing protocols for diabetic foot and pressure ulcers. Surg Technol Int. 2003;11:85-92. [PMID:12931288]

7. Eming SA, Brachvogel B, Odorisio T, Koch M. Regulation of angiogenesis: Wound healing as a model. Prog Histochem Cytochem. 2007;42(3):115-70. [PMID:17980716] http://dx.doi.org/10.1016/j.proghi.2007.06.001
8. Bao P, Kodra A, Tomic-Canic M, Golinko MS, Ehrlich HP, Brem $\mathrm{H}$. The role of vascular endothelial growth factor in wound healing. J Surg Res. 2009;153(2):347-58.

[PMID:19027922]

http://dx.doi.org/10.1016/j.jss.2008.04.023

9. Bates DO, Jones RO. The role of vascular endothelial growth factor in wound healing. Int J Low Extrem Wounds. 2003;2(2):107-20. [PMID:15866835] http://dx.doi.org/10.1177/1534734603256626

10. Thomas KA. Vascular endothelial growth factor, a potent and selective angiogenic agent. J Biol Chem. 1996;271(2): 603-6. [PMID:8557658] http://dx.doi.org/10.1074/jbc.271.2.603

11. Stojadinovic OK, Golinko M, Tamic-Canic M, Brem H. A novel, non-angiogenic mechanism of VEGF: Stimulation of keratinocyte and fibroblast migration. Wound Repair Regen. 2007;17(2):A30.

12. Jazwa A, Kucharzewska P, Leja J, Zagorska A, Sierpniowska A, Stepniewski J, Kozakowska M, Taha H, Ochiya T, Derlacz R, Vahakangas E, Yla-Herttuala S, Jozkowicz A, Dulak J. Combined vascular endothelial growth factor-A and fibroblast growth factor 4 gene transfer improves wound healing in diabetic mice. Genet Vaccines Ther. 2010;8:6. [PMID:20804557]

http://dx.doi.org/10.1186/1479-0556-8-6

13. Frank S, Hübner G, Breier G, Longaker MT, Greenhalgh DG, Werner S. Regulation of vascular endothelial growth factor expression in cultured keratinocytes. Implications for normal and impaired wound healing. J Biol Chem. 1995;270(21):12607-13. [PMID:7759509] http://dx.doi.org/10.1074/jbc.270.21.12607

14. Asadi MR, Torkaman G, Hedayati M. Effect of sensory and motor electrical stimulation in vascular endothelial growth factor expression of muscle and skin in full-thickness wound. J Rehabil Res Dev. 2011;48(3):195-201. [PMID:21480094] http://dx.doi.org/10.1682/JRRD.2009.11.0182

15. Morris KA, McGee MF, Jasper JJ, Bogie KM. Evaluation of electrical stimulation for ischemic wound therapy: A feasibility study using the lapine wound model. Arch Dermatol Res. 2009;301(4):323-27. [PMID:19050907] http://dx.doi.org/10.1007/s00403-008-0918-2

16. Bevilacqua M, Dominguez LJ, Barrella M, Barbagallo M. Induction of vascular endothelial growth factor release by transcutaneous frequency modulated neural stimulation in diabetic polyneuropathy. J Endocrinol Invest. 2007;30(11): 944-47. [PMID:18250616] http://dx.doi.org/10.1007/BF03349242

17. Schaffer MR, Tantry U, Gross SS, Wasserburg HL, Barbul A. Nitric oxide regulates wound healing. J Surg Res. 1996;63(1):237-40. [PMID:8661204] http://dx.doi.org/10.1006/jsre.1996.0254 
18. Stallmeyer B, Kämpfer H, Kolb N, Pfeilschifter J, Frank S. The function of nitric oxide in wound repair: Inhibition of inducible nitric oxide-synthase severely impairs wound reepithelialization. J Invest Dermatol. 1999;113(6):1090-98. [PMID:10594757]

http://dx.doi.org/10.1046/j.1523-1747.1999.00784.x

19. Frank S, Stallmeyer B, Kämpfer H, Kolb N, Pfeilschifter J. Nitric oxide triggers enhanced induction of vascular endothelial growth factor expression in cultured keratinocytes (HaCaT) and during cutaneous wound repair. FASEB J. 1999;13(14):2002-14. [PMID:10544183]

20. LoGerfo FW, Coffman JD. Current concepts. Vascular and microvascular disease of the foot in diabetes. Implications for foot care. N Engl J Med. 1984;311(25):1615-19. [PMID:6390204] http://dx.doi.org/10.1056/NEJM198412203112506

21. Rayman G, Williams SA, Spencer PD, Smaje LH, Wise $\mathrm{PH}$, Tooke JE. Impaired microvascular hyperaemic response to minor skin trauma in type I diabetes. Br Med J (Clin Res Ed). 1986;292(6531):1295-98. [PMID:2939920] http://dx.doi.org/10.1136/bmj.292.6531.1295

22. Shore AC, Price KJ, Sandeman DD, Green EM, Tripp JH, Tooke JE. Impaired microvascular hyperaemic response in children with diabetes mellitus. Diabet Med. 1991;8(7): 619-23. [PMID:1833113] http://dx.doi.org/10.1111/j.1464-5491.1991.tb01667.x

23. Flynn MD, Tooke JE. Aetiology of diabetic foot ulceration: A role for the microcirculation? Diabet Med. 1992;9(4): 320-29. [PMID:1600701] http://dx.doi.org/10.1111/j.1464-5491.1992.tb01790.x

24. Schäffer MR, Tantry U, Efron PA, Ahrendt GM, Thornton FJ, Barbul A. Diabetes-impaired healing and reduced wound nitric oxide synthesis: A possible pathophysiologic correlation. Surgery. 1997;121(5):513-19. [PMID:9142149] http://dx.doi.org/10.1016/S0039-6060(97)90105-7

25. Bulgrin JP, Shabani M, Chakravarthy D. Nitric oxide synthesis is suppressed in steroid impaired and diabetic wound healing. Wounds. 1995;7:48-57.

26. Kloth LC. Electrical stimulation for wound healing: A review of evidence from in vitro studies, animal experiments, and clinical trials. Int J Low Extrem Wounds. 2005;4(1):23-44. [PMID:15860450] http://dx.doi.org/10.1177/1534734605275733

27. Taylor RR, Sladkevicius E, Guest JF. Modelling the costeffectiveness of electric stimulation therapy in non-healing venous leg ulcers. J Wound Care. 2011;20(10):464,466, 468-72. [PMID:22067884]

http://dx.doi.org/10.12968/jowc.2011.20.10.464

28. Talebi G, Torkaman G, Firoozabadi M, Shariat S. Effect of anodal and cathodal micro-amperage direct current on the skin wound healing: A biomechanical and histological study. J Biomech. 2007;40(S2):S662.

http://dx.doi.org/10.1016/S0021-9290(07)70650-4

29. Recio AC, Felter CE, Schneider AC, McDonald JW. Highvoltage electrical stimulation for the management of stage III and IV pressure ulcers among adults with spinal cord injury: Demonstration of its utility for recalcitrant wounds below the level of injury. J Spinal Cord Med. 2012; 35(1):58-63. [PMID:22330192]

http://dx.doi.org/10.1179/2045772311Y.0000000044

30. Petrofsky JS, Lawson D, Berk L, Suh H. Enhanced healing of diabetic foot ulcers using local heat and electrical stimulation for $30 \mathrm{~min}$ three times per week. J Diabetes. 2010;2(1):41-46. [PMID:20923474]

http://dx.doi.org/10.1111/j.1753-0407.2009.00058.x

31. Peters EJ, Armstrong DG, Wunderlich RP, Bosma J, Stacpoole-Shea S, Lavery LA. The benefit of electrical stimulation to enhance perfusion in persons with diabetes mellitus. J Foot Ankle Surg. 1998;37(5):396-400, discussion 447-48. [PMID:9798171]

http://dx.doi.org/10.1016/S1067-2516(98)80048-3

32. Gilcreast DM, Stotts NA, Froelicher ES, Baker LL, Moss KM. Effect of electrical stimulation on foot skin perfusion in persons with or at risk for diabetic foot ulcers. Wound Repair Regen. 1998;6(5):434-41. [PMID:9844163] http://dx.doi.org/10.1046/j.1524-475X.1998.60505.x

33. Asadi MR, Torkaman G, Hedayati M, Mofid M. Role of sensory and motor intensity of electrical stimulation on fibroblastic growth factor-2 expression, inflammation, vascularization, and mechanical strength of full-thickness wounds. J Rehabil Res Dev. 2013;50(4):489-98.

[PMID:23934870]

http://dx.doi.org/10.1682/JRRD.2012.04.0074

34. Sebastian A, Syed F, Perry D, Balamurugan V, Colthurst J, Chaudhry IH, Bayat A. Acceleration of cutaneous healing by electrical stimulation: Degenerate electrical waveform down-regulates inflammation, up-regulates angiogenesis and advances remodeling in temporal punch biopsies in a human volunteer study. Wound Repair Regen. 2011;19(6): 693-708. [PMID:22092840]

http://dx.doi.org/10.1111/j.1524-475X.2011.00736.x

35. Zhao M, Bai H, Wang E, Forrester JV, McCaig CD. Electrical stimulation directly induces pre-angiogenic responses in vascular endothelial cells by signaling through VEGF receptors. J Cell Sci. 2004;117(Pt 3):397-405.

[PMID:14679307]

http://dx.doi.org/10.1242/jcs.00868

36. Bai H, Forrester JV, Zhao M. DC electric stimulation upregulates angiogenic factors in endothelial cells through activation of VEGF receptors. Cytokine. 2011;55(1):110-15. [PMID:21524919]

http://dx.doi.org/10.1016/j.cyto.2011.03.003 
37. Petrofsky J, Hinds CM, Batt J, Prowse M, Suh HJ. The interrelationships between electrical stimulation, the environment surrounding the vascular endothelial cells of the skin, and the role of nitric oxide in mediating the blood flow response to electrical stimulation. Med Sci Monit. 2007;13(9):CR391-97. [PMID:17767118]

38. Ferrer M, Sánchez M, Martín MC, Márquez-Rodas I, Alonso MJ, Salaices M, Balfagón G. Protein kinase A increases electrical stimulation-induced neuronal nitric oxide release in rat mesenteric artery. Eur J Pharmacol. 2004;487(1-3):167-73. [PMID:15033389] http://dx.doi.org/10.1016/j.ejphar.2004.01.030

39. Veves A, Akbari CM, Primavera J, Donaghue VM, Zacharoulis D, Chrzan JS, DeGirolami U, LoGerfo FW, Freeman R. Endothelial dysfunction and the expression of endothelial nitric oxide synthetase in diabetic neuropathy, vascular disease, and foot ulceration. Diabetes. 1998;47(3):457-63. [PMID:9519754]

http://dx.doi.org/10.2337/diabetes.47.3.457

40. Lawson D, Petrofsky JS. A randomized control study on the effect of biphasic electrical stimulation in a warm room on skin blood flow and healing rates in chronic wounds of patients with and without diabetes. Med Sci Monit. 2007; 13(6):CR258-63. [PMID:17534231]

Submitted for publication August 2, 2013. Accepted in revised form January 22, 2014.

This article and any supplementary material should be cited as follows:

Mohajeri-Tehrani MR, Nasiripoor F, Torkaman G, Hedayati M, Annabestani Z, Asadi MR. Effect of lowintensity direct current on expression of vascular endothelial growth factor and nitric oxide in diabetic foot ulcers. J Rehabil Res Dev. 2014;51(5):815-24.

http://dx.doi.org/10.1682/JRRD.2013.08.0174

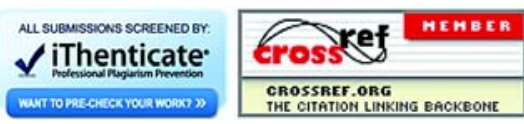

